\title{
APPLICATION OF TIME SERIES INSAR TECHNIQUE FOR DEFORMATION MONITORING OF LARGE-SCALE LANDSLIDES IN MOUNTAINOUS AREAS OF WESTERN CHINA
}

\author{
T. Qu a, b, P. Lu ${ }^{\text {a, b }}$, C. Liu ${ }^{\text {a, b, * }, H . ~ W a n ~}{ }^{\text {a, b }}$ \\ ${ }^{a}$ College of Surveying and Geo-Informatics, Tongii University, 1239 Siping Road, Shanghai, China - \\ (1989tengteng, luping, liuchun, 8lovehappy)@tongji.edu.cn \\ ${ }^{\mathrm{b}}$ Center for Spatial Information Science and Sustainable Development, Tongji University, 1239 Siping Road, Shanghai, China
}

\section{Commission I, WG I/2}

KEY WORDS: Large-scale Landslide, Western China, InSAR, Small Baseline InSAR, Time Series, Deformation Monitoring

\begin{abstract}
:
Western China is very susceptible to landslide hazards. As a result, landslide detection and early warning are of great importance. This work employs the SBAS (Small Baseline Subset) InSAR Technique for detection and monitoring of large-scale landslides that occurred in Li County, Sichuan Province, Western China. The time series INSAR is performed using descending scenes acquired from TerraSAR-X StripMap mode since 2014 to get the spatial distribution of surface displacements of this giant landslide. The time series results identify the distinct deformation zone on the landslide body with a rate of up to $150 \mathrm{~mm} / \mathrm{yr}$. The deformation acquired by SBAS technique is validated by inclinometers from diverse boreholes of in-situ monitoring. The integration of InSAR time series displacements and ground-based monitoring data helps to provide reliable data support for the forecasting and monitoring of largescale landslide.
\end{abstract}

\section{INTRODUCTION}

Landslide is recognized as a major type of natural hazards in Western China (Liu, Li et al. 2013). Especially after the 2008 Wenchuan Earthquake, lots of giant landslides have been triggered (Dai, Xu et al. 2011). As a result, landslide detection and early warning are of great importance in this region considering the severe consequences that large-scale landslides may induce.

The surface deformation measurement is often recognized as one of the most effective methods to monitor landslides and their movements. Among diverse landslide monitoring techniques, Interferometric synthetic aperture radar (InSAR) has great potential for detecting landslide deformation, which can overcome lots of limitations for in-situ observations (Massonnet and Feigl 1998, Ye, Kaufmann et al. 2004, Lu et al. 2014). In recent years, multi-temporal InSAR technique is used widely to exploit the time series deformation process in the landslide and has achieved many acknowledgements (Colesanti, Ferretti et al. 2003, Liu, Li et al. 2013). The availability of high resolution SAR such as the German Space Agency (DLR) TerraSAR-X (TSX) data with frequent repeat cycle (11 days) represents an opportunity for constructing frequent landslide displacement maps in our landslide study.

In this paper, we concentrate on the Xishancun Landslide in $\mathrm{Li}$ County of Sichuan Province and identify obvious surface displacements using SBAS technique with high resolution TerraSAR-X datasets acquired from 2014 to 2015. The landslide deformation map is constructed and distinct deformation areas are analyzed. Then time series surface displacements of diverse boreholes are validated by cumulative displacements obtained from inclinometers of in-situ sensors. The integration of SBAS time series results and ground-based monitoring data helps to better understand the landslide movement and provide reliable data support for landslide monitoring.

\section{ADVANCED INSAR TIME SERIES TECHNIQUES}

The Small Baseline method (Berardino, Fornaro et al. 2002, Casu, Manzo et al. 2006) is one of the multi-temporal InSAR solutions, which could take advantage of a stack of SAR interferograms to detect slow deformations with millimeter accuracy.

The SBAS method first generates many interferometric pairs with small spatial and temporal baselines in order to minimize the decorrelation effects and topographic errors. For a given unwrapped interferogram $\mathrm{j}$, the phase at pixel $(\mathrm{x}, \mathrm{r})$ (where $\mathrm{x}$ is the azimuth coordinate and $r$ is the slant range coordinates) computed from the SAR acquisitions at start time epoch and end time epoch can be written as follows (Berardino, Fornaro et al. 2002):

$$
\delta \phi_{j}(x, r)=\delta \phi_{j}^{\text {defo }}(x, r)+\delta \phi_{j}^{\text {topo }}(x, r)+\delta \phi_{j}^{a t m}(x, r)+\delta \phi_{j}^{\text {noise }}(x, r)
$$

where, $\delta \phi_{j}^{\text {defo }}$ represents the slant deformation phase between start time epoch and end time epoch; ${ }^{\delta \phi_{j}^{\text {topo }}}$ is the topographic phase error; $\delta \phi_{j}^{a t m}$ represents for temporal atmospheric variation and different SAR acquisition time; and ${ }^{\delta \phi_{j}^{\text {noise }}}$ accounts for the other noise sum (Zhao, Lu et al. 2012). 
The estimated linear deformation rate and DEM error could be subtracted from all unwrapped interferograms. Next, the atmospheric phase will be separated by high-pass filtering in temporal domain and low-pass filtering in spatial domain. Then, after the simultaneous operation of SVD and finite difference smoothing of the atmospheric corrected phase, the nonlinear deformation phase at different SAR acquisition dated will be calculated.

\section{STUDY AREA}

\subsection{Data}

A total of 9 StripMap descending TerraSAR images acquired between Nov. 2014 and May 2015 are used in our study. The $0.5 \mathrm{~m}$ high-resolution DEM acquired from terrestrial laser scanning is used to remove the topographic errors in SBAS processing chain. We set 100 days and $200 \mathrm{~m}$ as the thresholds for temporal and perpendicular baselines in generating the interferograms and selected 23 pairs in total.

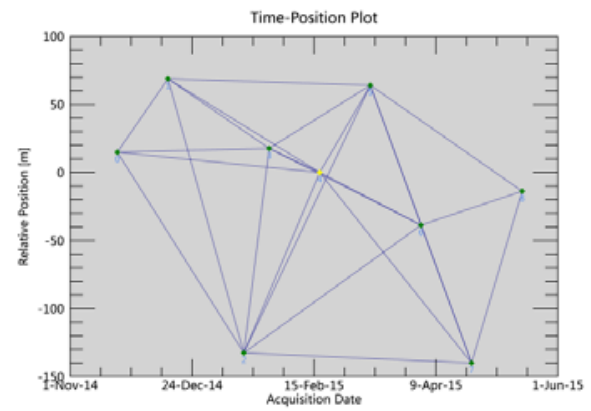

Figure 1. Spatial-temporal baselines of the generated interferograms. Points represent SAR images and numbered lines are the interfereometric pairs.

\subsection{Geological Setting of the Xishancun Landslide}

The Xishancun Landslide is located in Li County, Sichuan Province, south-western of China. This giant landslide is a typical large-scale landslide and seriously affected by the "5.12" Wenchuan Earthquake in 2008 (Qi, Xu et al. 2010). It poses severe threats to 317 National Road and villages both on the slope and at the foot of the mountain. The slope of Xishancun Landslide ranges from 25 to 55 degrees. The elevation of the leading edge is about $1500 \mathrm{~m}$ while the elevation of the trailing edge is about $2910 \mathrm{~m}$, thus creating an elevation difference of about $1410 \mathrm{~m}$. The landslide length is about $3800 \mathrm{~m}$, the minimum width is $680 \mathrm{~m}$ and the maximum width is $980 \mathrm{~m}$. The average thickness of the sliding body is $55 \mathrm{~m}$ and the scale amounted to $1.7 \times 10^{8} \mathrm{~m}^{3}$. A Spatial Sensor Network MUNOLD (Lu et al. 2015) is currently being deployed in monitoring this landslide.

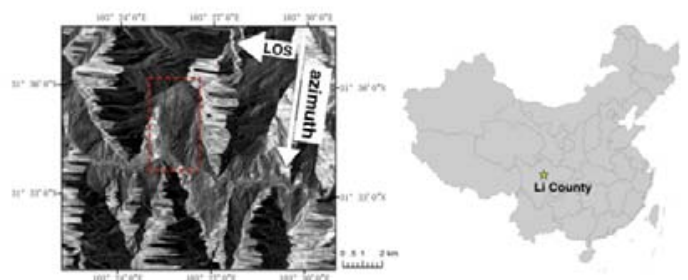

Figure 2. TerraSAR-X intensity image of Xishancun Landslide and Location of Li County in China

\section{TIME SERIES RESULTS}

\subsection{Mean Velocities}

Figure 3 shows the deformations rates acquired from the SBAS technique over the dataset-acquired period for Xishancun landslide. The distribution of identified surface deformation is mainly located in the middle and eastern lower part of the landslide body. The significant deformation have been detected in the hillside and showed to move away from the satellite with a mean velocity of more than $150 \mathrm{~mm} /$ year. And deformation over the east borderline area is also easily detected where many fissures are found during in-situ explorations. In the lower part of landslide body, deformation with a rate of $30 \mathrm{~mm} / \mathrm{year}$ could also be identified which is quite reasonable as lots of constructions of country roads are undergoing these years.

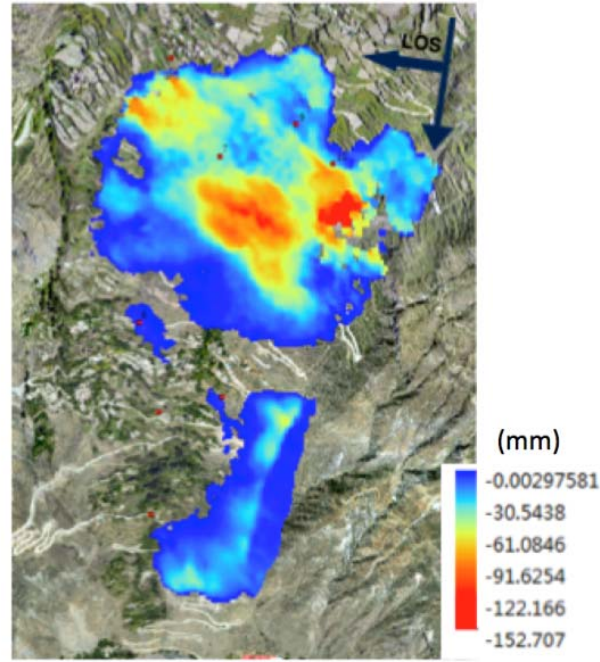

Figure 3. Landslide deformation velocity map

\subsection{Validation of InSAR Time Series}

The time series surface deformation of Boreholes (ZK5 and ZK7) has been compared with the inclinometers in the same period in this section. The InSAR time series results are displayed as time-displacement diagrams in Fig4. The X-axis reports the dates of SAR image acquisition and Y-axis shows the displacement values taken along the line of sight of the satellite. The positive value represents movement towards radar sensors, while the negative value represents movement away from radar sensors. From the figure, ZK5 shows slightly upward displacement, however, ZK7 shows significant downward movements.

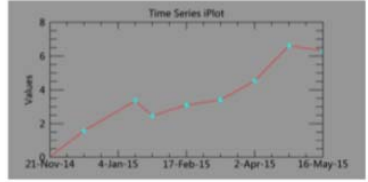

Time series displacements for ZK5

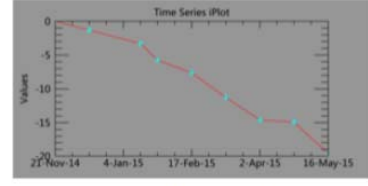

Time series displacements for ZK 7
Figure 4. Time series displacements of Boreholes acquired by SBAS technique (Unit of displacement value is $\mathrm{mm}$ )

Figure 5 illustrates the time series displacements of inclinometers in diverse depths of Boreholes. The positive value represents the displacement downwards along the maximum slope angle direction. Obviously the inclinometers of ZK5 
uniformly arched during the whole year period. While inclinometers of ZK7 indicate fluctuating downward trend. These validations confirm that the displacements measure along the LOS direction show the same deformation tendency with those of inclinometers.
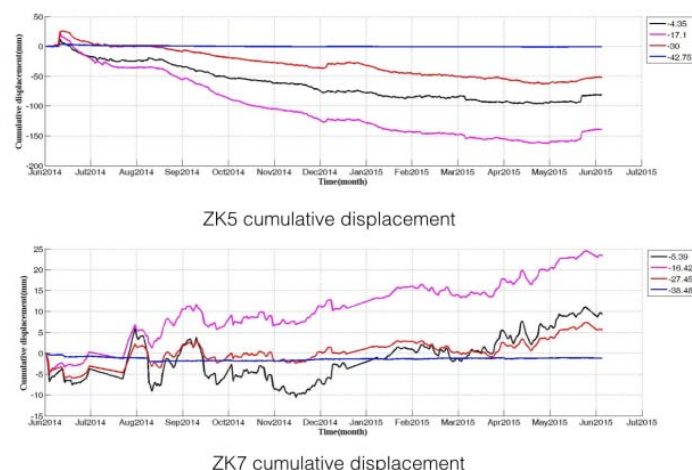

Figure 5. Time series displacements of inclinometers in diverse depths of Boreholes

\section{CONCLUSION}

In this paper, InSAR time series techniques have been successfully employed to identify surface deformation in Xishancun Landslide with TerraSAR-X scenes acquired from 2014 to 2015. The locations and active deformation areas of the landslide detected are in general in good agreement with in-situ monitoring and field investigations. Our case study clearly demonstrate that slow-moving landslide deformation could be measured and monitored effectively in Xishancun area by an advanced time series InSAR technique and X-band SAR datasets. Future studies will focus on a longer time span and scenes from diverse satellite orbits to get $2 \mathrm{D}$ or $3 \mathrm{D}$ deformation vector field. Correlation between time series InSAR datasets and in-situ sensors would be evaluated in future works as well.

\section{ACKNOWLEDGEMENTS}

This work was supported by the projects funded by the 973 National Basic Research Program (No. 2013CB733204)

\section{REFERENCES}

Berardino, P.; Fornaro, G.; Lanari, R.; Sansosti, E., 2002. A new algorithm for surface deformation monitoring based on small baseline differential SAR interferograms. Geoscience and Remote Sensing, IEEE Transactions on 40(11): 2375-2383.

Casu, F.; Manzo, M.; Lanari, R., 2006. A quantitative assessment of the SBAS algorithm performance for surface deformation retrieval from DInSAR data. Remote Sensing of Environment 102(3): 195-210.

Colesanti, C.; Ferretti, A.; Prati, C.; Rocca, F., 2003. Monitoring landslides and tectonic motions with the Permanent Scatterers Technique. Engineering geology 68(1): 3-14.

Dai, F.; Xu, C.; Yao, X.; Xu, L.; Tu, X.; Gong, Q., 2011. Spatial distribution of landslides triggered by the 2008 Ms 8.0 Wenchuan earthquake, China. Journal of Asian Earth Sciences 40(4): 883-895.
Liu, C.; Li, W.; Wu, H.; Lu, P.; Sang, K.; Sun, W.; Chen, W.; Hong, Y.; Li, R.., 2013. Susceptibility evaluation and mapping of China's landslides based on multi-source data. Natural hazards 69(3): 1477-1495.

Liu, P.; Li, Z.; Hoey, T.; Kincal, C.; Zhang, J.; Zeng, Q.; Muller, J.-P., 2013. Using advanced InSAR time series techniques to monitor landslide movements in Badong of the Three Gorges region, China. International Journal of Applied Earth Observation and Geoinformation 21: 253-264.

Lu, P.; Catani, F.; Tofani, V.; Casagli, N., 2014. Quantitative hazard and risk assessment for slow-moving landslides from Persistent Scatterer Interferometry. Landslides 11(4): 685-696.

Lu, P.; Wu, H.; Qiao, G.; Li, W.; Scaioni, M.; Feng, T.; Liu, S.; Chen, W.; Li, N.; Liu, C., 2015. Model test study on monitoring dynamic process of slope failure through spatial sensor network. Environmental Earth Sciences 74(4): 3315-3332.

Massonnet, D. and Feigl, K. L., 1998. Radar interferometry and its application to changes in the Earth's surface. Reviews of geophysics 36(4): 441-500.

Qi, S.; Xu, Q.; Lan, H.; Zhang, B.; Liu, J., 2010. Spatial distribution analysis of landslides triggered by 2008.5. 12 Wenchuan Earthquake, China. Engineering geology 116(1): 95108.

Ye, X.; Kaufmann, H.; Guo, X., 2004. Landslide monitoring in the Three Gorges area using D-InSAR and corner reflectors. Photogrammetric Engineering \& Remote Sensing 70(10): 11671172.

Zhao, C.; Lu, Z.; Zhang, Q.; de La Fuente, J., 2012. Large-area landslide detection and monitoring with ALOS/PALSAR imagery data over Northern California and Southern Oregon, USA. Remote Sensing of Environment 124: 348-359. 